\title{
A PEDAGOGIA VISUAL COMO FUNDAMENTAL NA EDUCAÇÃO DE SURDOS: SIGNIFICAÇÕES DO CORPO E AS EXPERIÊNCIAS VISUAIS DOS ALUNOS SURDOS
}

\author{
VISUAL PEDAGOGY AS FUNDAMENTAL IN THE EDUCATION OF THE DEAF: MEANINGS OF THE \\ BODY AND THE VISUAL EXPERIENCES OF DEAF STUDENTS
}

LA PEDAGOGÍA VISUAL COMO FUNDAMENTAL EN LA EDUCACIÓN DE LOS SORDOS: LOS SIGNIFICADOS DEL CUERPO Y LAS EXPERIENCIAS VISUALES DE LOS ESTUDIANTES SORDOS

https://orcid.org/0000-0001-8812-6529 Ellen Midiã Lima da Silva Gomes ${ }^{\mathbf{A}}$
$\underline{\text { https://orcid.org/0000-0002-4227-6625 Hector Renan da Silveira Calixto }}{ }^{\text {C }}$

${ }^{\text {A }}$ Universidade do Estado do Rio de Janeiro (UERJ), Rio de Janeiro, RJ, Brasil

${ }^{B}$ Universidade Federal do Oeste do Pará (UFOPA), Santarém, PA, Brasil

${ }^{\mathrm{C}}$ Universidade Federal do Oeste do Pará (UFOPA), Santarém, PA, Brasil

Recebido em: 15 out. 2020 | Aceito em: 19 ago. 2021 Correspondência: Ellen Gomes (ellenpedagoga9@gmail.com)

\section{Resumo}

Partindo do princípio que as práticas pedagógicas embasadas na experiência visual contribuem para um melhor aprendizado dos alunos surdos, este estudo investigou o uso do corpo como estratégia de mediação pedagógica durante a implementação do protocolo do Livro Digital Acessível (LDA) em duas turmas de surdos matriculados no $3^{\circ}$ ano do Ensino Fundamental I, em uma escola pública de Duque de Caxias/RJ, que adota como proposta pedagógica o Bilinguismo. Pretende-se neste texto analisar as representações visuais sobre o corpo enquanto suporte visual no processo de ensino e aprendizagem. A metodologia desta pesquisa embasouse na perspectiva histórico-cultural (FREITAS, 2002; SOUZA, 2001), com viés da pesquisa participante (TRIPP, 2005). Participaram do estudo três professoras da educação básica e quatro alunos surdos. Conclui-se que explorar o corpo enquanto recurso visual nas significações do mundo contribuiu para que os conteúdos fossem compreendidos pelos alunos; o corpo enquanto marca cultural carrega as impressões sociais e que a mediação pedagógica foi fundamental para que os assuntos abordados em aula fossem compreendidos.

Palavras-chave: Visualidade; Educação de surdos; Perspectiva histórico-cultural.

\begin{abstract}
Assuming that pedagogical practices based on visual experience contribute to better learning for deaf students, this study investigated the use of the body as a pedagogical mediation strategy during the implementation of the Accessible Digital Book (LDA) protocol in two enrolled deaf classes in the 3rd year of elementary school, in a public school in Duque de Caxias, RJ, which adopts bilingualism as a pedagogical proposal. The aim of this text is to analyze the visual representations about the body as a visual support in the teaching and learning process. The methodology of this research was based on the historical-cultural perspective (FREITAS, 2002; SOUZA, 2001), with a bias from the participant research (TRIPP, 2005). Three teachers of basic education and four deaf students participated in the study. It is concluded that exploring the body as a visual resource in the meanings of the world contributed to the contents being understood by the students; the body as a cultural mark carries social impressions and that pedagogical mediation was fundamental for the subjects covered in class to be understood.
\end{abstract}

Keywords: Visuality; Education of the deaf; historical-cultural perspective. 


\section{Resumen}

Partiendo del principio de que las prácticas pedagógicas basadas en la experiencia visual contribuyen a un mejor aprendizaje de los estudiantes sordos, este estudio investigó el uso del cuerpo como estrategia de mediación pedagógica en el período de la implementación del protocolo del Libro Digital Accesible (LDA) en dos clases de sordos estudiantes en el tercero año de la escuela de Duque de Caxias/RJ que adopta el Bilingüismo como propuesta pedagógica de enseñanza. Este artículo pretende analizar las representaciones visuales sobre el cuerpo como soporte visual en el proceso de enseñanza y aprendizaje. La metodología de investigación se basó en la perspectiva histórico-cultural (FREITAS, 2002; SOUZA, 2001), con un sesgo de la investigación participante (TRIPP, 2005). En el estudio participaron tres profesores de educación básica y cuatro estudiantes sordos. Se concluye que explorar el cuerpo como recurso visual en los significados del mundo contribuyó a que los contenidos fueran comprendidos por los estudiantes; el cuerpo como marca cultural lleva impresiones sociales y esa mediación pedagógica fue fundamental para la comprensión de los temas tratados en clase.

Palabras clave: Visualidad; Educación para sordos; Perspectiva histórico-cultural.

\section{Introdução}

Este trabalho ${ }^{i}$ tem como objetivo analisar as representações e significações visuais de alunos surdos sobre o corpo e utilizá-las como suporte visual durante as relações de ensino e aprendizagem dos conteúdos pelos alunos surdos, matriculados em duas turmas de $3^{\circ}$ ano do Ensino Fundamental I de uma escola pública, localizada em Duque de Caxias - RJ, que adota o Bilinguismo como metodologia de ensino de surdos.

A problematização desta pesquisa está estruturada em dois eixos centrais: visualidade presente na língua de sinais e desenvolvimento humano, a partir da perspectiva históricocultural.

A língua de sinais é uma língua gesto-visual, sendo realizada através de movimentos do corpo, das mãos, pelas expressões faciais e corporais. Assim, a presente discussão se faz necessária, pois os surdos utilizam majoritariamente o corpo para se comunicarem, uma vez que a enunciação ocorre por meio desse.

Partimos da compreensão que a utilização de uma prática educacional que corresponda ao caráter visual presente nas línguas de sinais (a visualidade) e tendo o signo visual como base do processo de ensino e aprendizagem (Pedagogia Visual), pode auxiliar os alunos surdos à assimilação melhor dos conteúdos abordados em sala de aula (CAMPELLO, 2008). Ao contrário, as maiores dificuldades educacionais enfrentadas por estudantes surdos ocorrem exatamente pela utilização de métodos descontextualizados que enfatizam a oralização, não a visualidade. 
Atualmente, a metodologia mais aceita por pesquisadores para a educação de surdos é o Bilinguismo. Neste enfoque, a experiência visual é intrínseca aos processos de ensino e aprendizagem. Para Skliar (2001, p.176):

[...] a experiência visual dos surdos envolve, para além das questões linguísticas, todo tipo de significações comunitárias e culturais, exemplificando: os surdos utilizam apelidos ou nomes visuais; metáforas visuais; imagens visuais, humor visual; definição das marcas do tempo a partir de figuras visuais, entre tantas outras formas de significações.

Nesse sentido, a Pedagogia Visual se refere à práticas que vão ao encontro dos elementos próprios da cultura surda e da língua de sinais. Vale ressaltar que apesar das línguas de sinais serem percebidas pela visão, estas apresentam as mesmas características de uma língua natural como, por exemplo, versatilidade e flexibilidade, arbitrariedade, criatividade e dupla articulação, como é exposto por Harrison (2014, p. 32):

1 Versatilidade e flexibilidade: qualidade que as línguas possuem de poder expressar qualquer sentimento, emoção, fazer indagações e referências aos tempos verbais;

2 Arbitrariedade: é a característica segundo a qual a forma da palavra (seja falada, escrita ou sinalizada) não tem relação direta com seu significado (...);

3 Criatividade/produtividade: são possibilidades que as línguas possuem de produzir infinitos enunciados a partir de um número infinito de fonemas ou quiremas; 4 Dupla articulação: é a característica das línguas de possuir um número finito de unidades (fonema e quirema) que isoladamente não tem significado. Apenas se forem combinados a outros fonemas/quiremas adquirem significados (HARRISON, 2014, p. 32).

As línguas de sinais apresentam ainda outras características, como a iconicidade e arbitrariedade. A iconicidade corresponde à propriedade que uma palavra ou sinal possui como base característica física do seu significado, por exemplo, é possível encontrar iconicidade no sinal de árvore, pois este é expressado fazendo alusão do tronco, das copas e da base. A arbitrariedade se refere aos signos que não fazem menção às características do significado, dessa maneira cada comunidade pode representar esta palavra de modo diferente, sem que sejam realizadas representações do sentido expressado (ALBRES, 2014, p. 83-84).

Wiliam Stokoe, primeiro linguista a considerar a ideia que a língua de sinais possui características inerentes de língua natural, apontou três parâmetros presentes na língua de sinais: configuração de mão (CM); ponto de articulação (PA) ou localização (L); e movimento (M) (GOÉS; CAMPOS, 2014). Quadros e Karnopp (2004) relatam que na década de 1970, com as novas investigações sobre a língua de sinais americana (ASL) foi acrescentado um parâmetro à língua de sinais pelos linguistas Robin Battison, Edward Klima e Ursulla Bellugi - a orientação de mão $(\mathrm{O})$, como mostra o Quadro 1: 
Quadro 1 - Parâmetros das línguas de sinais

\begin{tabular}{|c|c|l|}
\hline $\begin{array}{c}\text { Parâmetros das línguas de } \\
\text { sinais }\end{array}$ & Sigla & \multicolumn{1}{c|}{ Descrição } \\
\hline $\begin{array}{c}\text { Configuração da mão } \\
\text { Ponto de articulação ou } \\
\text { localização }\end{array}$ & PA ou L & $\begin{array}{l}\text { Formas de configurar as mãos para simbolizar } \\
\text { diversos sinais }\end{array}$ \\
\hline Movimento & M & Diferentes formas e direções da realização do sinal \\
\hline Orientação da mão & O & $\begin{array}{l}\text { Direção da palma da mão para a realização de um sinais são realizados } \\
\text { sinal }\end{array}$ \\
\hline
\end{tabular}

Fonte: Elaboração dos autores com base em Quadros e Karnopp (2004)

\section{Aprendizagem segundo a perspectiva histórico-cultural}

Voltando-nos para o desenvolvimento humano, a partir da perspectiva históricocultural, vemos que para Vigotski o desenvolvimento cultural é a principal esfera para que a deficiência seja compensada. Desta maneira, o uso da língua de sinais e recursos visuais para a educação de surdos não é um suprimento da falta da fala oral, antes é a criação de novas possibilidades de participação ativa e integral na sociedade (DAINEZ; SMOLKA, 2012). Isto porque a aprendizagem humana é para além do caráter biológico, sendo o funcionamento mental influenciado no decorrer das relações sociais, é marcado pela criação de signos e instrumentos, caracterizando a atividade mental.

Partindo desta premissa, o desenvolvimento acontece no entrelaçamento entre a estrutura orgânica e as vivências culturais, consequentemente as funções psicológicas superiores são de origem cultural, ou seja, até mesmo as ações mentais que demonstram o comportamento consciente do homem, como a linguagem, o pensamento, a atenção voluntária, a percepção, a memória e a imaginação são forjadas no social. Neste sentido, o meio é compreendido como fonte do desenvolvimento humano (VIGOTSKI, 2001; 2010).

Para pensarmos o entrelaçamento biológico e cultural, vale considerar a perspectiva de Vigotski, no qual o ser humano é compreendido como ser histórico, sendo sujeito ativo na construção de si mesmo, de sua própria história, não sendo resultado apenas do reflexo. Dessa forma, reiteramos a compreensão que o desenvolvimento humano não está unicamente fundamentado no biológico, como também, está ligado a interação do sujeito com o meio (SANTANA; BARONI, 2014). 
Para Vigotski (1998) existem dois tipos de mediadores fundamentais: os instrumentos e os signos. Os instrumentos apresentam uma finalidade e são direcionados para o mundo externo servindo como transmissores da influência humana e contribuindo para o desenvolvimento da relação do ser humano com o meio histórico-social (ARAÚJO, LACERDA, 2010).

Os instrumentos para Vigotski (1998) são considerados como recursos de intervenção entre o trabalho e o trabalhador, possibilitando as formas de transformação da natureza. Estes instrumentos não são escolhidos aleatoriamente, mas a partir de um objetivo, podendo ser considerado como um objeto social e mediador (OLIVEIRA, 1998).

Os signos, por sua vez, são direcionados internamente, tendo a capacidade de alterar o comportamento do ser humano e a organização das funções psicológicas superiores, sendo esta mudança a principal característica dos signos (VIGOTSKI, 1998; apud ARAÚJO; LACERDA, 2010). Podemos compreender os signos como componentes que simbolizam ou exteriorizam outros objetos, eventos e/ou situações (OLIVEIRA, 1998, p. 30), ou seja, o signo é a encarnação do material (FREITAS, 2002).

Vigotski (1996) salienta que os signos são mediadores das relações entre os homens e à medida em que estes são usados é reforçado o caráter social dos seres humanos. Araújo e Lacerda (2010) reiteram que a linguagem é um signo mediador entre o mundo cultural e biológico. Por meio da linguagem é possível a utilização de instrumentos auxiliares para que problemas relativos à atividade humana sejam resolvidos, possibilitando o planejamento de ações, direcionando a vontade e até mesmo controlando o comportamento. "As ações humanas, além de condicionadas por estímulos externos, são mediadas por signos" (ARAÚJO; LACERDA, 2006, p. 229).

Isto posto, reiteramos a ideia de que as relações de ensino, conforme compreendido por Souza, Dainez e Magiolino (2015), são um processo intenso de trabalho coletivo para a promoção de conhecimentos e para a formação dos sujeitos. Nesse sentido, o ensino voltado para os alunos com deficiência precisa construir novas oportunidades de participação da sociedade, deixando o paradigma assistencialista que dividia o conhecimento e não abrangia a visão de mundo (DAINEZ; SMOLKA, 2014).

\section{Caminhar metodológico}

Este estudo se caracteriza como uma pesquisa na perspectiva histórico-cultural (FREITAS, 2002; SOUZA, 2001), baseando-se no materialismo histórico-dialético que reconhece o ser humano como ser biológico e cultural. Assumindo as estratégias da pesquisa 
participante, que no âmbito educacional pode ser um dos modos para que professores e pesquisadores possam ressignificar suas práticas pedagógicas, buscou-se assim, nesta investigação, refletir sobre as relações de ensino e aprendizagem de alunos surdos, tendo a colaboração de professoras e alunos surdos de uma escola pública, localizada em Duque de Caxias - RJ.

Assim, para aproximação com o campo optou-se por realizar observação participante, utilizando como formas de registros: filmagem, preenchimento de uma ficha de registro e anotações em diário de campo (BOGDA; BIKLEN, 1994). A pesquisa de campo ${ }^{\text {iil }}$ aconteceu após um encontro inicial na escola, quando foi acordado os objetivos da pesquisa com a direção e professores, sendo definido que seria observada duas turmas de $3^{\circ}$ ano do Ensino Fundamental I durante seis dias. Desses, quatro dias foram destinados à aplicação do Livro Digital Acessível $(\mathrm{LDA})^{\mathrm{iii}}$ e dois dias para entrevistas com as professoras, além de uma entrevista com a direção da escola para levantamento de dados sobre a unidade escolar. O Quadro 2 a seguir apresenta a relação dos alunos que participaram da investigação.

Quadro 2 - Alunos participantes do estudo

\begin{tabular}{|l|l|l|l|}
\hline \multicolumn{1}{|c|}{ Nome (fictício) } & Idade & Turma & \multicolumn{1}{c|}{ Tipo de deficiência } \\
\hline Marcos & 8 anos & 302 & Surdez \\
\hline Leandro & 11 anos & 302 & Surdez e deficiência física \\
\hline Leonardo & 8 anos & 302 & Surdez \\
\hline Elton & 9 anos & 301 & Surdez \\
\hline
\end{tabular}

Fonte: Elaboração dos autores (2021)

Os alunos participantes desta pesquisa são moradores do município de Duque de Caxias. Dois apresentam surdez profunda e dois surdez moderada. Como é uma escola polo para ensino de alunos surdos de Duque de Caxias, houve a necessidade de formar uma classe bilíngue ${ }^{\mathrm{iv}}$ para auxiliar os alunos na aquisição da Libras. De acordo com as professoras participantes do estudo, muitos alunos chegam à escola sem o conhecimento da Libras.

As três professoras que participaram do estudo são bilíngues (Língua Portuguesa e Libras) e ministram as aulas em Libras. Lívia de 46 anos de idade atua na educação infantil e na classe multisseriada trabalhando especificamente com os alunos surdos. Márcia tem 57 anos 
de idade e atua há 23 anos com alunos surdos. Carla tem 54 anos de idade, leciona há 32 anos, sendo 16 anos com alunos surdos. Apresenta-se a seguir o Quadro 3 com os dados das professoras.

Quadro 3 - Professoras participantes do estudo

\begin{tabular}{|c|l|c|}
\hline $\begin{array}{c}\text { Nome } \\
\text { (fictício) }\end{array}$ & \multicolumn{1}{|c|}{ Formação } & Atuação na escola \\
\hline Carla & $\begin{array}{l}\text { Licenciada em Pedagogia e curso de interpretação } \\
\text { de Libras no Ines }\end{array}$ & Professora do $3^{\text {o }}$ ano \\
\hline Márcia & $\begin{array}{l}\text { Licenciada em Português, especialização em } \\
\text { orientação e supervisão educacional e curso de } \\
\text { Libras oferecido pela prefeitura }\end{array}$ & Professora do $3^{\mathrm{a}}$ ano \\
\hline Lívia & $\begin{array}{l}\text { Licenciada em Pedagogia e em fonoaudióloga, } \\
\text { especialista em psicomotricidade e educação } \\
\text { especial, Mestre em Informática da Educação }\end{array}$ & Professora de Informática \\
\hline
\end{tabular}

Fonte: Elaboração dos autores (2021)

A análise dos dados se deu por meio da análise microgenética e paradigma indiciário (embasado na semiótica), na qual foi realizado um trabalho minucioso, observando detalhadamente cada uma das transcrições, anotações do caderno de campo, além das fotos e filmagens (como os sujeitos desta investigação eram surdos, as expressões corporais e faciais foram fundamentais para a construção dos dados) (GOÉS, 2000).

\section{O corpo e as representações nas relações de ensino}

As informações apresentadas neste trabalho foram circunscritas ao tema gerador do conteúdo do LDA ${ }^{\mathrm{v}}$ : o corpo humano e cuidados de saúde. Desse tema foram elencadas três vertentes: corpo como suporte visual, corpo em sua dimensão histórico-cultural e mediação pedagógica.

\section{O corpo como suporte visual}

O corpo foi trabalhado como tema gerador no LDA, deste emergiu assuntos como: higiene, rotina e tipos de corpos. Como a língua de sinais é uma língua gesto-visual, a utilização do corpo como recurso visual facilitou a compreensão dos assuntos abordados. Vejamos uma situação da sala de aula:

Antes de trabalhar com o tema corpo no LDA a professora Carla levou para a sala de aula um cartaz com a silhueta de um corpo humano e algumas fichas contendo palavras das partes do corpo. A proposta era trabalhar com os alunos as partes do corpo.

Ao pegar uma das fichas a professora perguntava o que aquela palavra significava.

Conforme os alunos respondiam a professora apontava para seu próprio corpo elou 
corpo dos alunos a parte do corpo referida e pedia para que eles fizessem a datilologia (as palavras que os alunos não sabiam a professora apontava e fazia a datilologia).

Além de perguntar sobre qual parte do corpo aquela palavra representava a professora indagava sobre a sua função no corpo humano, trabalhando com diversos conceitos, como por exemplo, ao mostrar a ficha com a palavra OLHO a professora perguntava a função deste órgão e os alunos respondiam: para ver as cores, os animais, etc (Diário de campo, 2018).

Figura 1 - Cartaz do corpo humano

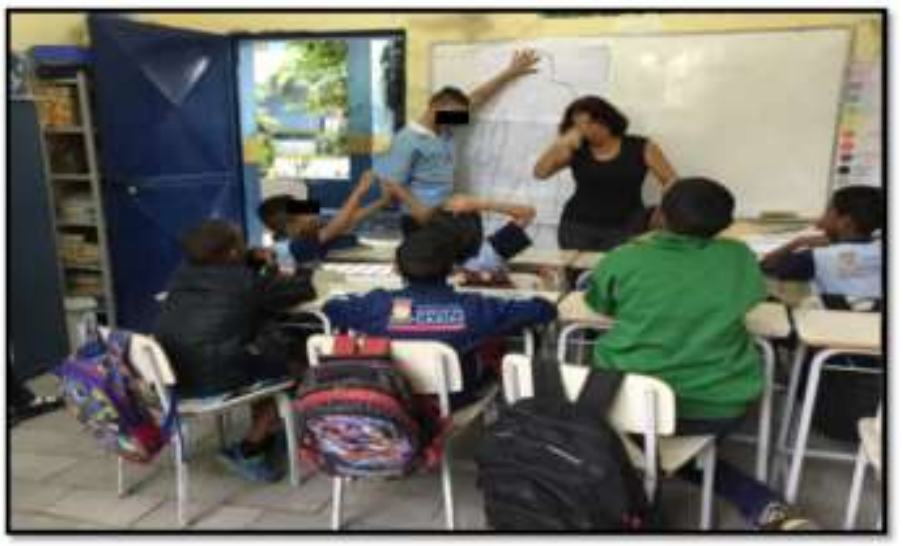

Fonte: Arquivo ObEE (2018)

Para Campello (2008), a visualidade é considerada como a aplicação de exercícios imagéticos mediados semioticamente. Esses exercícios se dão com a presença dos signos, constituindo-se como discurso por produzir signos e por ser reproduzida por signos. Ao usar o corpo como suporte visual as professoras deram ao corpo novas interpretações, estas por sua vez foram ressignificadas para que os signos trabalhados pudessem ser compreendidos.

Ainda em relação ao uso do corpo como recurso visual foram observadas duas situações: o uso de classificadores e o uso do corpo para reforçar o assunto abordado. Analisando o corpo pela dimensão semiótica podemos compreendê-lo como um elemento de comunicação, representação e expressão de subjetividades. Para Costa, Silva e Souza (2013) dependendo do contexto cultural em que o corpo está inserido, este apresentará diferentes funções. Campello (2008) ainda considera o corpo como parte da linguagem imagética. Assim, cada gesto corporal carrega uma intencionalidade.

Nessa linha, segundo Bakhtin a linguagem está presente em vários lugares, não caracterizando apenas a língua oral, esta apresenta um movimento dialógico, ou seja, contêm "gestos de respostas à teoria em um movimento de aproximação e distanciamento entre o que apreendemos e o que é apreendido" (FANTI, 2003, p. 96).

De acordo com a teoria bakhtiniana a língua é viva, contudo, essa vida só existe na comunicação dialógica, na comunicação de sentidos. Fanti (2003) compreende que o princípio 
dialógico da linguagem se constitui na abordagem social ao compartilhar com o outro, não sendo um processo independente, antes sendo um processo interacional.

Embasado nesta concepção bakhtiniana compreendemos o aspecto ético e estético do corpo como uma forma de interação e de comunicação, como um componente semiótico, ou seja, o corpo como representação de significado, como por exemplo, os gestos. Vale dizer que para Harrison (2014) os gestos são um dos componentes presentes na língua de sinais. Por meio deles é possível transmitir significados. Vejamos a situação a seguir:

Durante a aula sobre higiene a professora Lívia mostra uma imagem de um cortador de unha no LDA e pergunta para os alunos: o que aquela imagem representa? Imediatamente o aluno Elton faz o classificador de cortar a unha, incorporando o objeto e o ato de cortar a unha. Livia ao ver o aluno fazendo uso do classificador confirma que a representação está correta e também faz o classificador de cortador de unha (Diário de campo, 2018).

Figura 2 - Classificador de cortador de unha

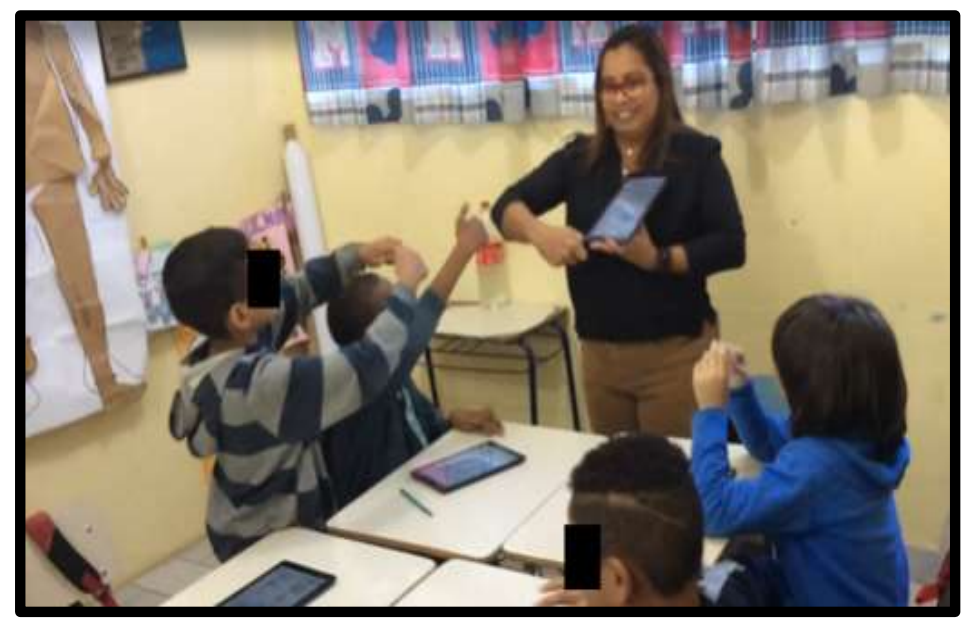

Fonte: Arquivo ObEE (2018)

Diferentes mecanismos podem ser utilizados para representar uma situação por meio do próprio corpo, uma das formas é através dos classificadores. Segundo Quadros e Karnopp (2004, p.127) são considerados classificadores:

- Fazer sinal em um local particular;

- Direcionar a cabeça e os olhos (e talvez o corpo) na direção relevante, simultaneamente à realização do sinal;

- Usar a apontação ostensiva numa localização particular;

- Usar um classificador na localização relevante;

- Usar um verbo direcional (também chamado de verbo de concordância), incorporando os referentes previamente introduzidos no espaço (grifo nosso). 
De acordo com Quadros (2014), os classificadores são conceituados como expressões da forma de um objeto, alguém ou coisa. Essas representações são usadas por meio das configurações das mãos que faz a forma do objeto representado. A incorporação, ou seja, o uso do próprio corpo no discurso em Libras é frequentemente usado. Segundo Albres (2014), a sintaxe espacial (espaço à frente do corpo do sinalizador) é usada para representar personagens ou ser inanimados que não estão presentes no momento da fala.

Ainda em relação ao corpo como recurso visual utilizado para auxiliar a compreensão do conteúdo, a professora Lívia ao falar sobre os cuidados que devemos ter com nosso corpo mostrou uma imagem no livro de um curativo, imediatamente os alunos se manifestaram e mostraram onde haviam se machucado.

O primeiro aluno aponta para o pé e fala que machucou o dedo, o segundo aluno como estava usando uma calça com um rasgo no joelho mostrou a professora seu joelho machucado, como não deu para ver bem ele ficou em pé, levantou a calça e mostrou para a turma o joelho machucado. O terceiro aluno ao ver que a professora tinha um curativo mostrou seu joelho machucado e pediu para a professora colocar o curativo nele (Diário de campo, 2018).

Figura 3 - Alunos mostrando pé e joelho machucados
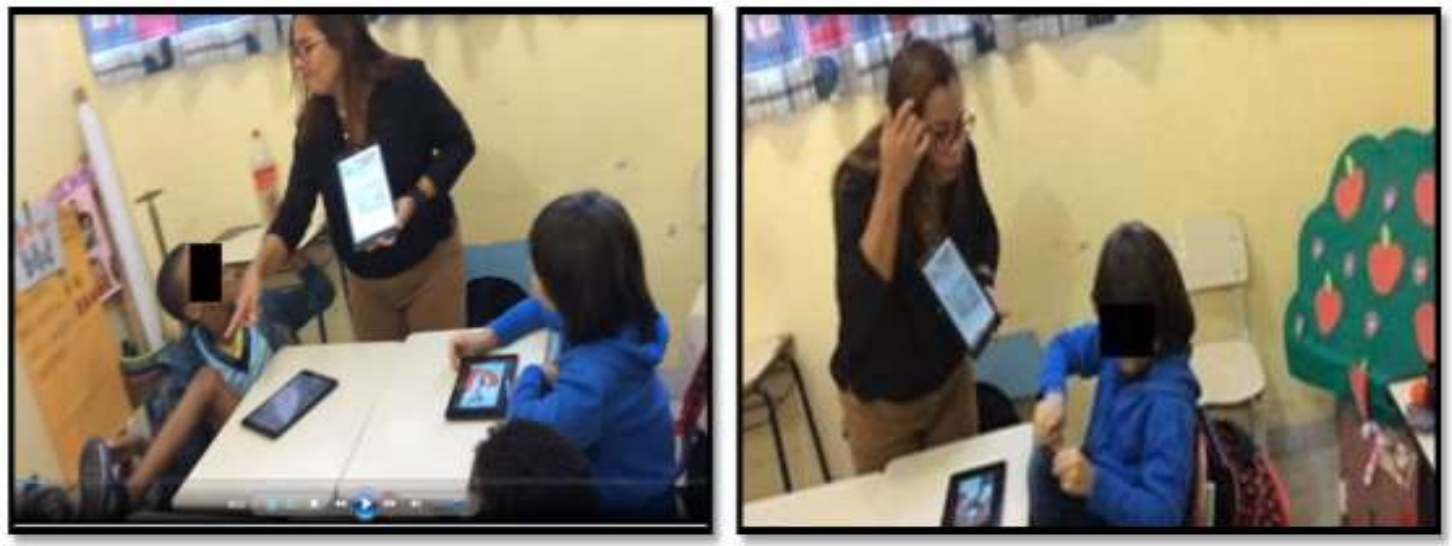

Fonte: Arquivo ObEE (2018).

O uso do classificador e das expressões corporais possibilitou que o assunto abordado pela professora fosse entendido pelos alunos. Isto ocorreu de forma participativa, na qual os alunos e a professora trabalharam em conjunto para a construção deste entendimento.

\section{O corpo em sua dimensão histórico-cultural}

Um outro aspecto que nos chamou atenção em relação ao acesso ao conteúdo do LDA foi a percepção que os alunos têm dos seus próprios corpos. Soares (2001), explica que o corpo não é apenas biológico, antes carregam simbologias das marcas sociais. O corpo é o local onde emergem e se manifestam os desejos, as sensações e as emoções. Por meio do corpo demonstramos os tipos de normas que seguimos e como nos portamos (MARZANOPARISOLI, 2004). 
Para Bourdieu (2006), o corpo é cunhado pela impressão social, ou seja, as normas da sociedade marcam o corpo de tal forma que o faz agir, andar, falar e até pensar de acordo com as ideologias presentes no meio em que este corpo se insere. Soares (2001) reitera o pensamento de Bourdieu, argumentando que os corpos são educados:

Os corpos são educados por toda realidade que os circunda, por todas as coisas com as quais convivem, pelas relações que se estabelecem em espaços definidos e delimitados por atos de conhecimento. Uma educação que se mostra como face polissêmica e processo de um modo singular: dá-se não só por palavras, mas por olhares, gestos, coisas, pelo lugar onde vivem (SOARES, 2001, p. 110).

Compreendendo o corpo como marca cultural, um fato nos chamou bastante atenção. Durante o período da pesquisa os alunos tiveram dificuldades para reconhecer nas imagens a cor de pele e o tipo de cabelo que mais pareciam com eles. Os alunos negros apontavam sempre para as imagens de cor de pele branca e com cabelo liso. A atividade pedia que os alunos selecionassem as imagens que representavam o tipo de cabelo e a cor de pele dos alunos:

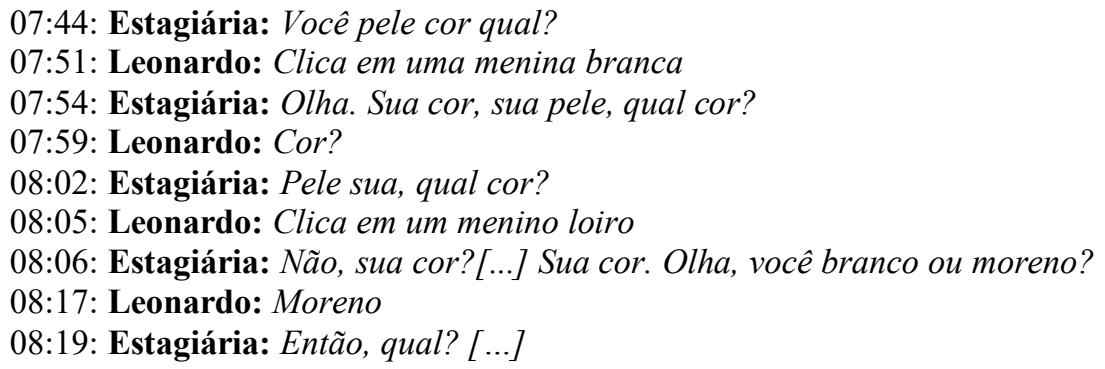

Na situação relatada, Leonardo de oito anos que é um aluno negro, não relacionou as imagens à sua cor de pele e tipo de cabelo. Primeiramente o aluno escolheu uma imagem de uma menina branca, com a intervenção da estagiária o aluno escolheu um menino loiro, ao ser questionado pela estagiária, Leonardo ficou confuso e, continuou a selecionar a imagem de um menino Loiro. Assim, a estagiária pediu para que o aluno olhasse para o seu braço e perguntou, sua cor é igual a qual? Com a persistência da estagiária o aluno aponta para a imagem do menino negro no livro.

Figura 4 - Estudante selecionando a cor de sua pele 


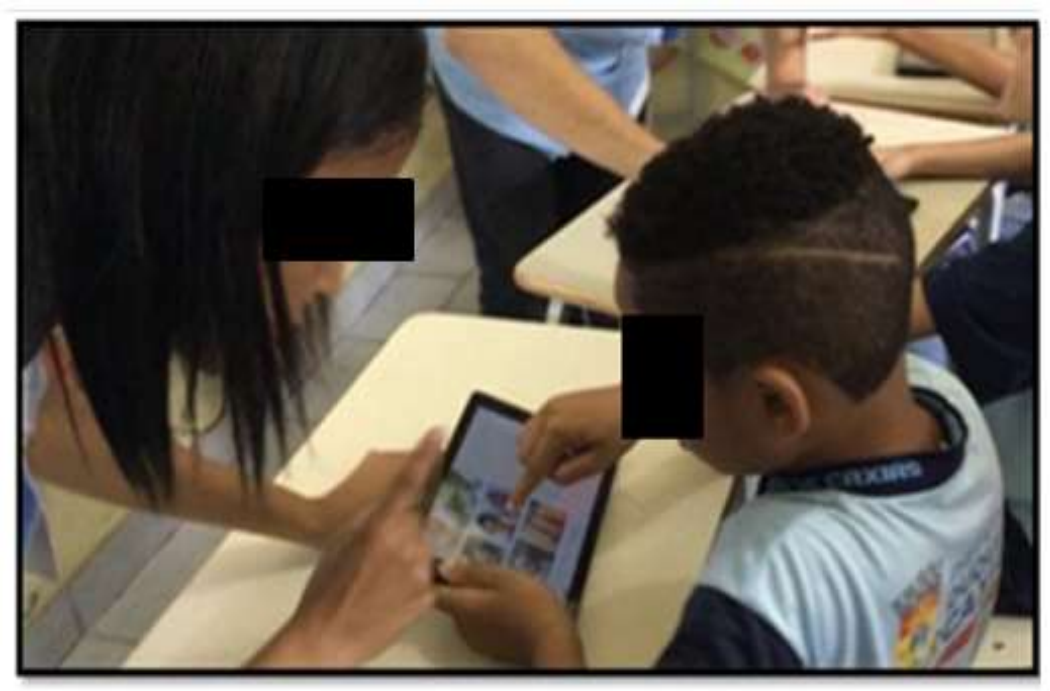

Fonte: Arquivo ObEE (2018)

Ao perceber que outros alunos não estavam conseguindo responder essa atividade, as professoras pegam um espelho pequeno e pedem para que os alunos se olhem. Ao se verem os alunos fazem expressão de dúvida, após a insistência das professoras e da estagiária os alunos respondem a questão do LDA (Diário de campo, 2018).

Vejamos essa situação em sala de aula:

14:48: Estagiária: Cabelo seu cacheado... Olha (pedindo ao aluno para se ver no espelho).

14:56: Márcia: Olha a dificuldade de compreender qual é o tipo do cabelo deles.... Ele foi no clarinho e a gente não sabe como é a questão familiar, então... Ele colocou um cabelo clarinho loiro como se fosse o dele.

15:31: Leandro: Coça a cabeça e faz expressão de não saber.

16:12: Márcia: É dificuldade de se perceber.

16:20: Carla: Amor, vê la seu cabelo, o cabelo... vê lá... Seu cabelo (pedindo ao aluno para se olhar no espelho novamente e responder no LDA).

16:30: Leandro: Chama a professora Márcia e mostra o cabelo parecido com o seu. 16:33: Márcia: Esse, muito bem.

Compreendemos que o fato dos alunos escolherem figuras diferentes das que os representam pode ter influência social. A hipótese levantada nesta pesquisa é que, como a cultura surda é visual, os alunos se associaram à pele branca por ser a imagem mais utilizada na mídia e nos desenhos, fazendo com que os estudantes se reconheçam como brancos, "um dos traços da própria branquidade, isto é, uma pessoa pode perfeitamente identificar-se como branca, mesmo que não possua brancura" (CARDOSO, 2010, p. 51). Contudo, não aprofundaremos a discussão nessa temática, visto que não é o foco desta pesquisa.

Soares (2001, p. 5), ainda considera o corpo como "primeiro plano da visibilidade humana, como lugar privilegiado das marcas da cultura". O corpo carrega marcas das experiências vivenciadas e pelo modo como esse corpo se expressa é possível perceber estigmas construídos socialmente como repressão ao corpo deficiente, magro, alto, gordo e como este corpo se adapta às normas fixadas pela sociedade. 
Apresentaremos a seguir o uso da mediação pedagógica realizada pelas professoras. Essas estratégias foram essenciais para que os conteúdos abordados nas aulas ganhassem significado, vejamos.

\section{Mediação Pedagógica}

Durante a análise das informações, percebemos que em todo o transcorrer da pesquisa, a mediação pedagógica foi fundamental para a compreensão do conteúdo trabalhado. Retomamos aqui o conceito de mediação de Vigotski. $\mathrm{O}$ autor considera que a ação do professor, ou seja, o trabalho docente em si no processo de ensino e aprendizagem é uma forma de mediação. Denominamos esta ação como mediação pedagógica.

Para o autor, a mediação, aqui no caso a pedagógica, só é possível pela linguagem, em um processo em que a atenção é centralizada na própria situação problema de aprendizagem, na qual o aluno começa a desenvolver sua atividade cognitiva. $O$ aluno busca nas suas experiências signos já estabelecidos para compreender algo novo (FONTANA, 1996).

$\mathrm{Na}$ observação durante o período da pesquisa, vimos que conforme os alunos apresentavam dúvidas e dificuldades na realização das atividades, as professoras intervinham e exemplificavam a partir do cotidiano dos alunos, como na atividade que perguntava quais esportes os alunos gostavam de fazer.

\footnotetext{
Nesta atividade o aluno Marcos estava com dificuldade para responder qual esporte mais gostava de brincar, com isso a professora começou a perguntar quais brincadeiras o aluno tinha prazer em fazer e indaga se o aluno brincava na rua. Marcos conta para a professora com quais amigos recreava-se na rua e fala que sempre joga futebol. Nessa conversa a professora busca entender o que mais o aluno simpatizava em fazer e se apreciava ou não esportes. Ao término da conversa o aluno seleciona a atividade no LDA que representa ofutebol (Diário de campo, 2018).
}

A partir deste exemplo, vemos que a escola como instituição social deve estabelecer com os alunos relações entre o conteúdo abordado em sala de aula com o que é vivido fora dela. Para os alunos surdos esta contextualização apresenta grande importância, pois a maioria teve pouco contato com os falantes de sua língua, ocasionando assim, dificuldades para assimilação dos conceitos (LACERDA; SANTOS; CAETANO, 2014).

O diálogo estabelecido possibilitou que o aluno pensasse sobre sua rotina e a forma como se relaciona com seus amigos. Araújo e Lacerda (2010) explicam que as funções psicológicas superiores da criança são formadas por meio da relação com a palavra. Essa relação possibilita que a criança se aproprie da cultura em que está imersa e que ela tenha consciência do mundo ao seu redor. 
Vigotski (1998) ainda ressalta que a aprendizagem é um processo social, sendo o diálogo e as diversas funções da linguagem fundamentais para o desenvolvimento cognitivo. $\mathrm{O}$ outro, no caso o professor, apresenta um papel fundamental, pois ele é responsável por estabelecer esse diálogo.

Dando sequência à situação relatada acima, a professora observa a próxima atividade e percebe que o aluno continua com dificuldade para responder a questão que perguntava qual parte do corpo é utilizado para se jogar futebol?

\author{
00:01: Márcia: Olha, você gostar bola? Futebol? \\ 00:10: Marcos: Sim (acena com a cabeça) \\ 00:12: Márcia: Pé, perna, braço, qual? \\ 00:15: Marcos: Bola \\ 00:19: Márcia: Bola, jogar mãos ou perna? \\ 00:22: Marcos: Perna \\ 00:23: Márcia: Isso, pé (digitaliza pé) chutar? \\ 00:32: Marcos: Sim
}

Para que o aluno entendesse a atividade a professora exemplifica o conteúdo do LDA com a realidade vivenciada por ele. Como o futebol é praticado pelo aluno, conforme a professora o indaga sobre as partes do corpo que ele usa para jogar, este responde bola, pois ao mencionar futebol, a bola foi o primeiro signo acionado. Posteriormente a professora usa o signo bola e insere uma nova pergunta: “BOLA, JOGAR MÃOS OU PERNA?” Esta indagação fez o aluno entender o que estava sendo solicitado na questão.

Pela interação da professora com o aluno, por meio do trabalho pedagógico, o entendimento foi estabelecido. Vigotski compreende que a relação do sujeito com o meio ou o outro social não ocorre de forma direta, mas sim de forma mediada. Para o autor, os signos medeiam as ações humanas, por meio dele é que constituímos a linguagem, o pensamento, a memória, a emoção (SOUZA, 2001).

Assim, vimos que a aprendizagem está ligada ao modo como os indivíduos participam e se apropriam das práticas sociais. É por meio do contato com o outro que nos apropriamos dos conhecimentos (SMOLKA, et al. 2007).

Voltando à análise dos dados, vimos outra situação na qual a estratégia de mediação pedagógica foi central para que o aluno compreendesse o conteúdo do LDA, vejamos:

\footnotetext{
Ao trabalhar com o signo corpo as professoras fizeram uma dinâmica com a turma contextualizando as partes do corpo: PÉ, BRAÇO, CABEÇA, ORELHA, PERNA e pediam para que os alunos explicassem para que servia essas partes do corpo. Para esta atividade foram utilizadas algumas fichas contendo a palavra escrita em português e um cartaz com uma silhueta de um corpo humano.

Os alunos tiveram dificuldade de compreender o significado da palavra pé, alguns falavam que era chulé, outros que era sapato ou meia. Como os alunos não estavam entendendo a professora Márcia pediu que um aluno tirasse o tênis e mostrasse o pé, só assim eles entenderam o que era (Diário de campo, 2018).
} 
Figura 5 - Signo pé

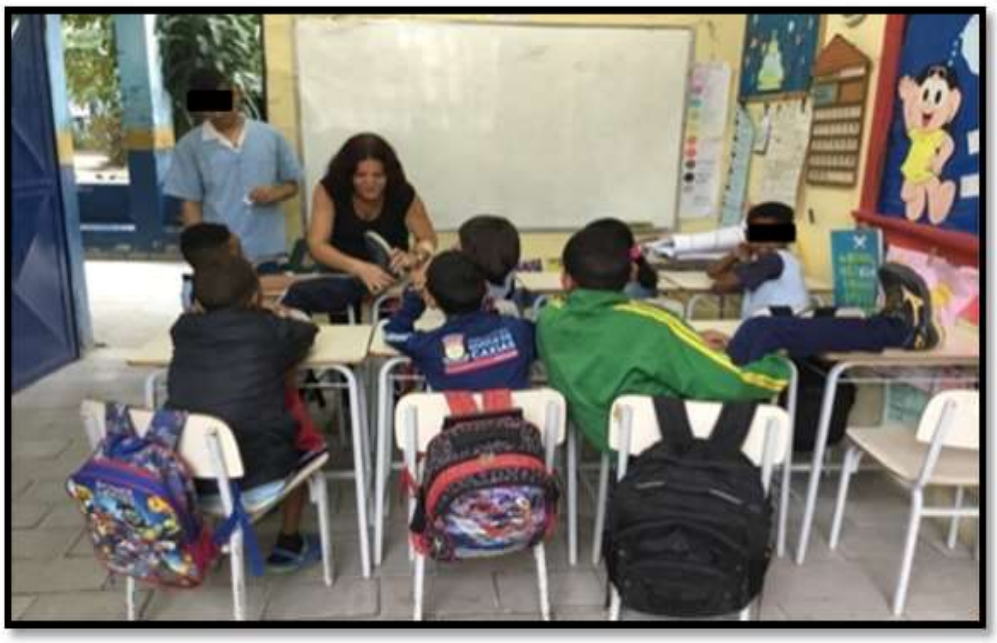

Fonte: Arquivo ObEE (2018)

O ato da professora de mostrar o pé do aluno foi uma forma de intervenção para que os alunos compreendessem o conceito de pé. Este entendimento foi forjado na relação estabelecida na sala de aula. Lacerda, Santos e Caetano (2014, p. 186) explicam que, para os alunos surdos, os conceitos são estabelecidos de forma visual, comparando-se a um filme que "contém cenas explorando a simultaneidade e a consecutividade dos eventos”.

Com esses exemplos, vimos que a utilização de estratégias visuais no processo de mediação contribui para a formação dos conceitos nos alunos surdos, pois a apresentação em Libras do assunto não é suficiente para que os conteúdos sejam assimilados, antes é preciso um trabalho com signos em língua de sinais, explorando assim as características visuais da língua (LACERDA; SANTOS; CAETANO, 2014).

Por meio das trocas de experiências em sala de aula que o conceito de pé ganhou significado. Isto reforça a ideia de que somos seres dialéticos e não apenas biológicos. Para Souza (2001), com base nos estudos de Vigotski, o desenvolvimento humano não está atrelado somente ao biológico, antes se configura como um processo histórico e cultural. Os seres humanos se constituem como sujeitos à medida que os aspectos biológicos e culturais se interrelacionam ininterruptamente (SOUZA, 2001).

Outro exemplo da centralidade da estratégia de mediação pedagógica desenvolvida foi quando as professoras trabalharam sobre o signo orelha.

Os alunos tiveram dificuldade para entender a funcionalidade da orelha, pois como os surdos não tem o aparelho fonador preservado a orelha acabou ficando despercebida para os alunos. Mais uma vez as professoras intervieram e deram exemplos de como a orelha pode ser usada no corpo humano, não servindo apenas para ouvir (Diário de campo, 2018). 
05:36 - Carla: Surdo ter, mas não escutar. Vocês surdos, alguns ouvir pouco, outros, surdos profundos igual Marcos e Leonardo. Orelha ter no corpo porque usar para colocar aparelho. Orelha toda pessoa ter, mas nem todos escutar. Ouvinte ter orelha e escutar, vocês ter orelha mas não escutar.

07:13 - Gabriela: Aparelho orelha eu usar

07:56 - Carla: Aqui ela ter brinco e piercing na orelha (se referindo a estagiária surda). Orelha usar aparelho, brinco... Poder cortar? Como cortar orelha? Não poder.

Figura 6 - Contextualização da orelha
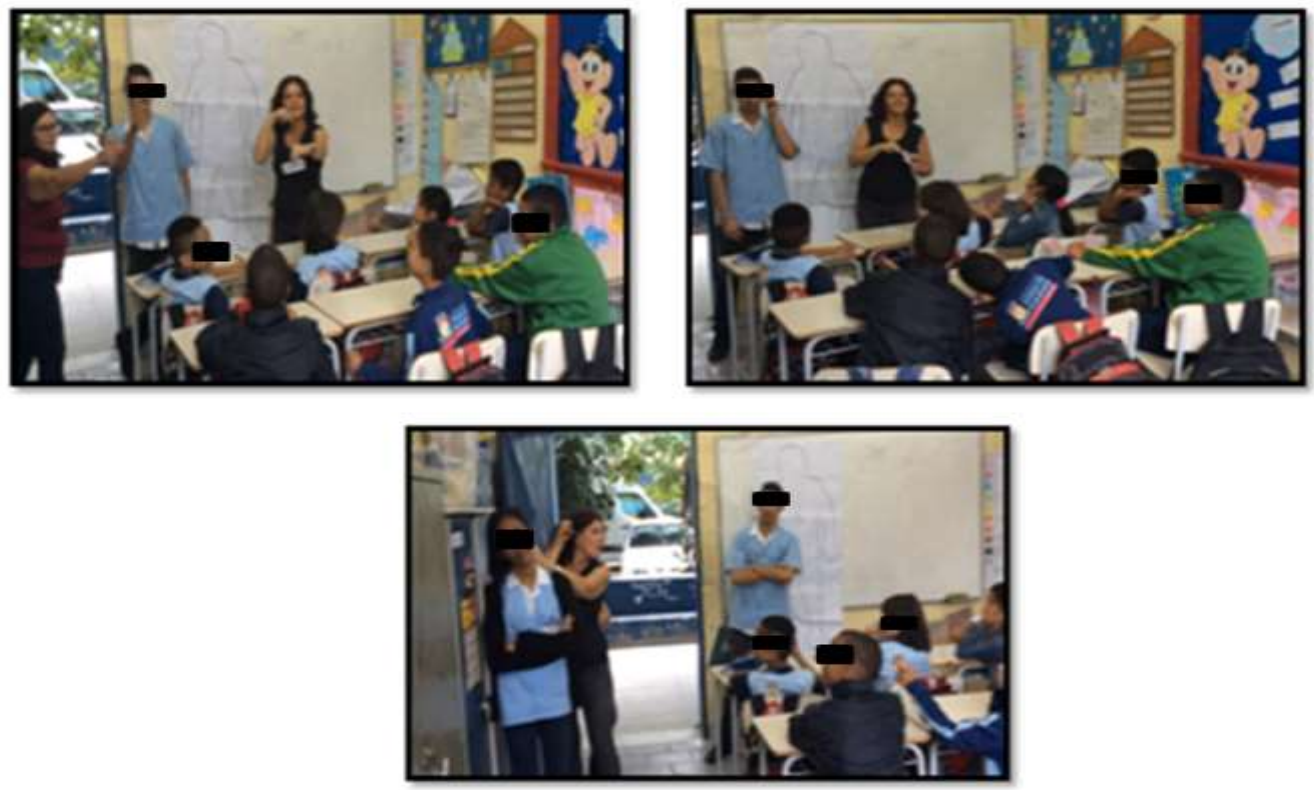

Fonte: Arquivo ObEE (2018).

Os alunos perceberam que apesar de não ouvirem, a orelha é uma parte importante do corpo e que podem usá-la de outras formas, não sendo inferiores aos ouvintes pela falta da audição. Os alunos achavam que pelo fato de não ouvirem não precisavam da orelha. Com a intervenção da professora eles viram que a orelha também é um membro importante do corpo humano.

\section{Considerações Finais}

Neste estudo vimos que a utilização do corpo enquanto suporte visual para o ensino de alunos surdos corroborou para que os assuntos abordados em aula fossem significados pelos estudantes. Como a língua de sinais possui um caráter visual, a não utilização dos recursos visuais para o ensino de surdos pode resultar em dificuldades de aprendizagem, e estas não ocorrem pela incapacidade do surdo em aprender, mas sim pelos métodos defasados.

Desta forma, compreendemos que parte dos problemas relacionados ao ensino de surdos ocorre pelo uso de materiais pedagógicos descontextualizados e que enfatizam o português, não tendo um ensino pensado a partir do bilinguismo e da visualidade. Vale lembrar que a proposta 
do bilinguismo, como o nome já diz, não é o uso unicamente da língua de sinais, antes, reconhece a Libras como L1 do surdo e o português na modalidade escrita como L2 (CAMPOS, 2013).

Fontana (1996, p. 19) preconiza que "a mediação do outro desperta na mente da criança um sistema de processos complexos de compreensão ativa e responsiva, sujeito às experiências e habilidades que ela já domina". Nessa mesma linha, aponta ainda que Vigotski compreende que a escolarização deve ser mediada socialmente pelo professor e pelos alunos com seus pares, sendo no decorrer das relações sociais que os sujeitos se apropriam dos conhecimentos presentes na sociedade em que vivem (FONTANA, 1996).

Compreendemos que esta pesquisa pode inspirar outras investigações quanto ao uso da Pedagogia Visual na educação de surdos, reconhecendo a importância do Bilinguismo e da valorização das especificidades da cultura surda e das línguas de sinais.

\section{Referências}

ALBRES, N. de A. A construção dos sinais e sua mobilidade específica. In: LACERDA, C. B. F. de; SANTOS, L. F. dos. (Org.) Tenho um aluno surdo, e agora? Introdução à Libras e educação de surdos. São Carlos: Edufscar, 2014. p. 81 - 98.

ARAÚJO, C. C. M; LACERDA, C. B. F. Linguagem e desenho no desenvolvimento da criança surda: implicações histórico-culturais. Psicologia em Estudo, Maringá, v. 15, n. 4, p. 695-703, out./dez. 2010.

ARAÚJO, C. C. M; LACERDA, C. B. F. Atividades simbólicas e o desenvolvimento inicial da escrita da criança surda bilíngue. In BERBERIAN, A. P; ANGELIS, C. M; MASSI, G (Orgs). Letramento: referências em saúde e educação São Paulo: Plexus, 2006. p. 221-243.

BOGDA, R.; BIKLEN, S. K. Investigação qualitativa em educação: uma introdução à teoria e aos métodos, Porto, Portugal, Porto editora, 1994. (Coleção ciências da educação).

BOURDIEU, Pierre. O camponês e seu corpo. Revista de sociologia e política, Curitiba, n. 26, 2006.

CAMPELLO, Ana Regina e Souza. Aspectos da visualidade na educação de surdos. 2008. Tese (Doutorado) - Universidade Federal de Santa Catarina, 2008.

CAMPOS, M. de L. I. L. Educação inclusiva para surdos e as políticas vigentes. LACERDA, C. B. F. de; SANTOS, L. F. dos. (Org.) Tenho um aluno surdo, e agora? Introdução à Libras e educação de surdos. São Carlos: Edufscar, 2013. p. 37 - 62.

CARDOSO, L. Retrato do branco racista e anti-racista. Revista Reflexão e ação, v. 18, n. 1, p. 46-76, 2010.

COSTA, M. T. M de S; SILVA, D. N. H; SOUZA, F. F. Corpo, atividades criadoras e letramento. São Paulo, Summus, 2013.

DAINEZ, D.; SMOLKA, A. L. B. Condições de desenvolvimento humano, educação (inclusiva) e psicologia histórico-cultural: inspirações, inquietações e implicações. REUNIÃO DA ANPED, v. 35, 2012. 
DAINEZ, D; SMOLKA, A. L. B. O conceito de compensação em Vigotski com Adler: desenvolvimento humano, educação e deficiência. Educ. Pesquisa, São Paulo, v. 40, n.4, p. 1093-1108, 2014.

FANTI, M. da G. C. A linguagem em Bakhtin: pontos e pespontos. Veredas-Revista de Estudos Linguísticos, v. 7, n. 1-2, 2003.

FONTANA, R. A. C. Mediação pedagógica na sala de aula. Campinas, Autores Associados, 1996.

FREITAS, M. T. de A. A abordagem sócio-histórica como orientadora da pesquisa qualitativa. Cadernos de pesquisa, n.1, p.21-39, 2002.

GOÉS, M. C. R, de. A abordagem microgenética na raiz histórico-cultural: uma perspectiva para o estudo da constituição da subjetividade. CEDES, n.50, 2000.

GOÉS, M. C. R; CAMPOS, M. de L. I. Aspectos da gramática da Libras. LACERDA, C. B. F. de; SANTOS, L. F. dos. (Org.) Tenho um aluno surdo, e agora? Introdução à Libras e educação de surdos. São Carlos: edufscar, 2014. p. 65 - 89.

HARRISON, K. M. P. Libras: apresentando a língua e suas características. (Org.) Tenho um aluno surdo, e agora? Introdução à Libras e educação de surdos. São Carlos: Edufscar, 2014. p. $27-36$.

LACERDA, C. B. F. de; SANTOS, L. F. dos; CAETANO, J. F. Estratégias metodológicas para o ensino de alunos surdos. (Org.) Tenho um aluno surdo, e agora? Introdução à Libras e educação de surdos. São Carlos: Edufscar, 2014. p. 185-200.

MARZANO-PARISOLI, M. M. Pensar o corpo. Petrópolis, RJ: Vozes, 2004.

OLIVEIRA, M. K. de. Vygotsky: Aprendizado e desenvolvimento: um processo sóciohistórico. São Paulo: Scipione, 1998.

QUADROS, R. M. Educação de surdos: efeitos de modalidade e práticas pedagógicas.

MENDES, EG; ALMEIDA, MA.; WILLIAMS, LCA (Org.). Temas em educação especial, 2014. p. 55-60.

QUADROS, R. M; KARNOPP, L. B. Lingua de Sinais Brasileira; estudos linguísticos. Porto Alegre: Artmed. 2004.

SANTANA, F. D; BARONI, V. As raízes marxistas do pensamento de Vigotski:

contribuições teóricas para a psicologia histórico-cultural. Kínesis, v. 6, n. 12, 2014.

SMOLKA, A. L. B; LAPLANE, A. N; NOGUEIRA, A. L. H; BRAGA, E. S. Relações de ensino. Rio de Janeiro, 2007.

SOARES, C. L. Corpo, conhecimento e educação: notas esparsas. In: SOARES, C. L. (Org.) Corpo e História. Campinas, SP: Autores associados, 2001. p. 108-129.

SOUZA, F. F. de. O corpo dança: com(tra)dições e possibilidades de sujeitos afásicos. 2001. Dissertação (Mestrado em educação) - Universidade Estadual de Campinas, Campinas, São Paulo.

SOUZA, F. F; DAINEZ. D.; MAGIOLINO. L. L. S. Educação e Desenvolvimento Humano: Modos de Mediação e Participação nos Meandros das Práticas Educacionais Inclusivas. In: PLETSCH, M. D.; MENDES, G. M. L.; HOSTINS, R. C. L. (orgs.). A escolarização de alunos com deficiência intelectual: políticas, práticas e processos cognitivos. Editora M\&M/ ABPEE, São Carlos, 2015, p. 15-30. 
SKLIAR, C. Os Estudos Surdos em Educação: problematizando a normalidade. In: SKLIAR, C. (Org.) A Surdez: um olhar sobre as diferenças. 2. ed. Porto Alegre: Mediação, 2001, p. 732.

TRIPP, D. Pesquisa-ação: uma introdução metodológica. São Paulo: Educação e Pesquisa, v.31, n.3, p. 443-466, 2005.

VIGOTSKI, L. S. A construção do pensamento e da linguagem. São Paulo: Martins Fontes, 2001.

VIGOTSKI, L. S. Semionovitch. Obras Escogidas V. Fundamentos de defectologia. Madrid: Visor, 1996.

VIGOTSKI, L. S. Quarta aula: a questão do meio na pedologia1, 2. Tradução de Márcia Pileggi, 2010.

VIGOTSKI, L. S. Pensamento e Linguagem. Rio de Janeiro: Martins Fontes, 1998.

\footnotetext{
${ }^{i} \mathrm{O}$ presente texto é fruto de uma dissertação de Mestrado na área de Educação, que teve como foco central o debate sobre o papel dos recursos visuais, pensados com base nos princípios da pedagogia visual, elaborados para composição de um livro didático digital acessível, como suporte de acesso ao conteúdo pelos alunos surdos.

ii Aprovado pelo Comitê de Ética da UFRRJ atendendo a resolução 466/12, com o número de processo 23267.00959/2017-76.

iii Este estudo está inserido em um projeto coletivo de pesquisa "Desenho Universal para a aprendizagem: implementação e avaliação do protocolo do livro digital acessível" coordenado pela prof. ${ }^{a}$ Dr. ${ }^{a}$ Márcia Denise Pletsch.

iv Os alunos surdos que chegam à escola e ingressam do primeiro ao quinto ano são recebidos em uma classe bilíngue. As aulas nessa etapa são ministradas integralmente em Libras, sendo utilizado o português na modalidade escrita como segunda língua (L2). A partir do sexto ano de escolaridade os alunos vão para a classe regular com a presença de um intérprete.

"O conteúdo do protótipo do LDA foi retirado do capítulo do livro "Porta Aberta: ciências humanas e da natureza" de 2015, para o $1^{\circ}$ ano ensino fundamental. O capítulo tinha como tema gerador o corpo humano e os cuidados com a saúde abordando as seguintes dimensões: partes do corpo, rotina diária e higiene.
} 